\title{
GLOBAL ENGLISH IN ITS LOCAL CONTEXTS: MANIFESTATIONS OF THE SOCIAL ENGLISH LANGUAGE STRATIFICATION IN NAMIBIA. PART 2: ANALYSIS OF SELECTED WRITTEN TEXTS
}

Keywords: Global English, the Outer Circle, English in Namibia, social variation

\begin{abstract}
The ever more popular and global use of English in the world is an undeniable fact. One of the obvious manifestations of this process is the selection of English as an official language, typically in former post-colonial states. Its global status, however, also motivates some African and Asian countries which have never been a part of the British Commonwealth to choose this tongue as an official state language (sometimes - the only official language) too. Does this decision assume that the citizens of those states know English fluently? How is English integrated in their everyday life? The case study of Namibian newspaper articles and personal advertisements from classified pages as well as billboard texts is an attempt to offer some insights into the use of the variety of English typical of this country both in the official and private milieu in writing. The objective of the study, presented in two parts (Part 1: theoretical background and Part 2: analysis of data) is to outline the unique context of the use of English in Namibia and describe the most characteristic features of Namibian English grammar when compared to Standard British English and on the basis of the results illustrate the existence of a social dialect continuum with regard to the use of the English language to be detected in the analysed written texts.
\end{abstract}

\section{The data}

Following the context of the study and the background information presented in Part 1 of the paper the issue to be discussed in Part 2 will be some aspects of written 
Namibian English. The choice of such a source of material was dictated by the fact that for the sake of a fairly reliable description of a language a suitable number of linguistic items are needed and a wider representation of their use in order to be able to describe some translocal, possibly national trends. One needs to bear in mind, though, that the population of Namibia, as said before, is only ca. 2 million citizens, the elites being of former European (Afrikaner, German, British, Portuguese) descent, while the lower strata represent African population, primarily of the Ovambo tribe, further followed by Kavango, Damara, Herero, Nama, and Himba tribes as well as a number of smaller ones, like Mbukushu in the north-east, some descendants of the Bushmen (San) tribes, and finally representatives of mixed races (cf. Stell 2009, 2014). It is therefore expected that the level of the command of English will vary across the social strata, which will be reflected in the samples of the language. In order to meet the above objective the most obvious and easily accessible source of data appeared to be newspaper articles and advertisements as well as billboard texts, since these are numerous, have a wide circulation and can reflect the language of a variety of users. As a rule, the most typical choice of a material for a study of a variety of English is the spoken medium, yet it has been assumed here that the selection of written texts, beside the greater ease of access to the material, will produce samples of language which have been thought through and re-read - the fact that they may still contain some local features or departures from the officially followed norm is therefore to be viewed as a sign of more deeply ingrained patterns of language use functioning in the investigated speech community. These may finally stabilize and form the foundation of a newly emergent variety.

We will begin our overview with a brief discussion of eight newspaper articles divided into six newspaper reports (excerpted from New Era, September 2013 and The Namibian, September 2013) dealing with internal and local socio-political issues, and two newspaper columns devoted to some local issues (New Era, September 2013, The Namibian, September 2013). This will be followed by the analysis of 50 billboard texts. Our overview of grammar and spelling of written texts will end with the most informal and individual level, represented by personal advertisements. The choice is necessarily quite limited, but such a selection offers an overview of written Namibian English at different levels of formality, with an objective to identify the acrolectal (press releases, billboards), mesolectal (newspaper columns, some billboards) and basilectal (personal advertisements) variants of written Namibian English. ${ }^{1}$

\section{Press releases}

Six texts were scanned in search of possible grammatical departures from Standard British English. They were three articles from New Era of 6 September 2013

The choice of the terms, i.e. acrolect, mesolect and basilect, which are primarily used in the analysis of a post-creole continuum, has been applied here after Platt (1975; cf. Mesthrie 2009: 302-303), who suggested that these terms should also be used in the description of the continuum of subvarieties within New Englishes, depending on their degree of divergence from the native English norm. Yano (2001) also uses the terms acrolect and basilect in order to refer to the standard and colloquial use of a given variety of New Englishes, respectively. 
concerning an infant mortality report, the appointment of new diplomats, and a case of a criminal released on bail (of 542, 329 and 154 words, respectively), and three articles from The Namibian of 24, 26 and 30 September 2013 (of 275, 296, and 426 words, respectively). The overview of the articles, written by six different authors, five of them of African background, did not reveal any significant departures from SBrE. The primary differences detected when juxtaposed with SBrE were five cases of the use of articles, four in text 1 and one in text 2. They were: (1) two positions up from the number 92 ranking of last year, (2) the health component alone received the low ranking, (3) Namibia is ranked at $\emptyset 124^{\text {th }}$ position (4) rising by ten places to $\underline{\emptyset} 6^{\text {th }}$ position, and (5) diplomats are the mirrors that reflect the image. Thus, it can be seen that the departures are of two kinds: either the (definite) article is used where it is not expected, or else the article is omitted where it should, according to SBrE rules, be used. The departure from the SBrE norms concerning articles is indeed quoted as a feature of New Englishes in general, as indicated in Part 1 (cf. Kirkpatrick 2007; Mesthrie, Bhatt 2008; Jenkins 2009, 2014). Some presence of such a kind of variation is indeed to be expected too, considering the level of difficulty that the use of articles poses for non-native speakers of English in general.

Moreover, in texts 5 and 6 two examples of a misused comma could be detected. One involved the use of a comma in the defining relative clause, viz. (6) the cemetery is one among others, which the council feels should be made available as a matter of urgency, which makes the designation of the cemetery referred to in the text rather ambiguous. The other, on the contrary, introduces a comma where it should not be used, i.e. between the subject of the sentence and the predicate, viz. (7) Two teachers from six schools in the Hardap Region, were selected late last year, which does make the sentence ungrammatical. It thus needs to be noted that the complicated rules for the use of commas, especially in the case of relative clauses, may cause occasional problems to users of English in the Outer Circle, but the flaws are very limited in their occurrence in official printed texts.

Finally, in text 4 a modification of a different kind was detected, namely the use of an incomplete phrase to put into practice, which is truncated here to (8) she cannot wait to put what she had learned at the training, hoping that it will not only improve the pass rate at the schools..., the omission of the to practice element may, however, have been unintended. Otherwise, the texts are well formed examples of formal Standard English - as the media have always provided their addressees with a model of language use, it is to be expected that in a country like Namibia, with one official language, and one that has not grown out of the local use, offering people an example to follow is particularly important.

\section{Billboards}

The texts on billboards cover a large variety of topics, starting with official boards of institutions, like ministries, universities, and schools advertising their services, through various types of regulations, warnings and reminders, down to the publicity of a variety of products, e.g. fast Internet, credit cards, electricity, water saving systems, car spare parts, beer, tourism and a variety of services, like shops, hair 
dressers, clothing, food. The scanning of 50 boards revealed hardly any departures from the standards of British English spelling and grammar, in keeping with the official acrolectal variant to be expected in the given context (and only in the case of private or small business notices possibly mesolectal), e.g., (9) Make Namibia a better place with education, - advanced certificate of education (ACE), - honours Bachelor of Education (BEdHons); (10) Luka Optics. Express Service. Same Day Glasses. Eye Test. Contact Lenses. Glasses. Sunglasses, or (11) Mini Magic Discounters. We don't meet prices. We beat them. Among the recorded texts only five cases of diversion from the standard have been recorded. The first two appear on a notice board at an official historical site (12) Entering of old buildings is at own risk. Some of the buildings could be unsafe. Thus, a non-standard use of of after the verb enter points to the author's non-native use of prepositions, and own risk without one's or your also indicates lack of familiarity with the use of indefinite pronoun. The third item concerns a spelling issue, viz. (13) Manufacturers, supplier \& distributers. Household and industrial cleaning materials (...), where distributor appears with an 〈e〉. Although the online Collins Dictionary does list the two options, various Internet discussion forums show that users disagree with the -er ending, while Wiktionary describes it as obsolete, and thus the form appears to be marked. Another somewhat ambiguous case is (14) Sale, repair and maintain all types of sewing machine \& parts. It is unclear whether the three first items combined by and are meant to be verbs or nouns. If verbs, then the word sale is used incorrectly instead of sell, and if nouns, then maintain is a faulty one. Also the use of the expression sewing machine in singular is not typical, especially without any article before it. Likewise, the use of the plural of spare in (15) Auto repairs. Spares and tyres instead of spare parts rings a slightly more local tone than the widespread British standard.

Thus, it appears that public notices of any kind demonstrate the use of standard English, especially those sponsored by governmental agendas (it is slightly less correct when private billboards are taken into consideration, however), possibly also as a way of teaching the public the English language, whose command, as will be shown in the next section, is frequently not in keeping with the norms of SBrE. At this point the reader's attention needs to be drawn to two more aspects of the use of English on the billboards. The first is the type of a positive encouragement that the billboards transmit with the help of the English texts, the strong patriotic feelings and sense of responsibility that they attempt to plant in recipients' hearts. Texts such as (16) It's great to be Namibian. My Namibia, my Spar or (17) Air Namibia. Carrying the spirit of Namibia, Super ACSE. Advanced Certificate of Secondary Education. Grade 5 to 12 teachers. Register now! IOL Institute for Open Learning. 10o\% proudly Namibian. Education is the greatest equaliser, (18) Born and brewed in Namibia. Tafel Lager. Share your pride. Not for sale to persons under the age of 18. Drink Responsibly are very frequent and they seem to perform two tasks - in the overt manner they enhance the prestige of the country in the eyes of its citizens, as well as the sense of unity among a variety of tribes, and in the covert manner they also work towards the status planning and prestige planning of the English language as the language of the country (cf. Deumert 2009). 
In this context it is also worth pointing out that English is not the only language that can be seen on billboards and notices, which is a reflection of the mixed linguistic history of Namibia. There are areas, notably the former German southwestern settlements like Lüderitz and Swakopmund, which show an interesting combination of two or even three languages in public places, i.e. English, German, and Afrikaans, despite their being numerically minority languages in Namibia, yet, as it appears, still locally quite prestigious (cf. Stell 2009). Such notices as, e.g. (19) Erholungsheim. Holiday Flats and Conference Facilities, (20) Namaqua. Vleismark. Meat Market. Fleischmarkt, or (21) Apteek. Pharmacy. Apotheke abound in that part of the country. Local tribal tongues, on the other hand, do not feature in such contexts - an example of an official written text, rare to find, was an instruction concerning the route towards the so-called White Lady pre-historic site, which was written in Nama. The only local word which proves to be quite visible on a variety of buildings along the roads is shebeen, i.e. 'an unlicensed drinking establishment, especially in Ireland, Scotland, and South Africa,' from Irish síbin 'illicit whiskey, place where such whiskey is sold' (www.thefreedictionary.com/shebeen). Its presence indirectly points to the character of activities which local tongues may be associated with. A peculiarity of the local use is no doubt the English word barber found frequently in names of various facilities, it, however, appears to be on the way out from British English, having made way for the term hairdresser. In Namibia, however, barber appears to be the generic word indicating this service, side by side with hair salon. Thus, it may be concluded that while English is strongly imposed upon the society, with all the positive connotations being built around it, the former prestigious languages, German and Afrikaans are allowed, though not encouraged, whereas the local tongues do not have a public presence, most likely not to provoke any possible divides within the state.

\section{Newspaper columns}

In this section a handful of comments are offered with regard to the two newspaper columns selected for analysis, i.e. "Adieu Windhoek - enter Oshakati" (New Era, 6 September, 2013, 741 words) and "Be a tourist in your own city" (The Namibian, 27 September, 2013, 1049 words). The reason why this discussion comes separately from newspaper reports and after billboards is that such texts have a much more personal character, being offered regularly by the same author and passing on private views, than the two categories above, and hence the degree of responsibility for the quality of their form and the messages they carry is lower compared to official news. Thus, in one of the analyzed texts the columnist is saying good bye to her readers after three years of her internship in the newspaper and recalls various persons she worked with along the way as well as different moments which helped her to develop her journalistic skills. It may be gathered from the text (and the photo attached, which shows a woman of African background) that the writer is young, which may account for certain practices she uses in the text, but also her fairly limited experience with the use of English in the semi-formal mode. As she says in the column, her main preoccupation was to write about community stories, and hence the topic made the 
texts much less formal and more personal in approach, which at the same time allows us to get a glimpse of a more relaxed way of expression. Some similar, though not as detailed conclusions can be drawn about the author of the other column, also a woman of African descent, as can be judged by the surname, clearly a native of Windhoek, the capital city, which she describes with a fair degree of detail and fondness. The text ends with a personal invitation of the author to take part in a photo competition and a reference to the possible prize to be won for it, and is full of personal jocular comments adding up to its sense of greater informality, which makes it rather different in tone from the press releases discussed above. Both of them can therefore be treated as examples of the acrolectal to the mesolectal stage in the quality of the language in its written variant, thereby opening a possibility for some linguistic idiosyncrasies and altering the standard.

The overview of the texts does point to a number of linguistic departures from the SBrE norm at the grammatical level (spelling-wise no departures from the standard have been spotted, however) as well as some locally marked uses of the language. The most visible grammatical issue can be seen in sentence (text I) (22) acknowledging your support, sincere and love you have devoted to me through my tenure, in which the word sincere, an adjective, appears to stand for the noun sincerity. This may point to the writer's unfamiliarity with this Latinate vocabulary item and word formation related to it. Also the use of through appears to be somewhat stylistically marked, as the word throughout or in the course of would be more typical of Standard English. Likewise, phrase (23) friendly in providing the information (text I) shows a certain departure from the norm as regards the use of the preposition, which would rather be expressed by in terms of, as regards, etc. Text II, on the other hand, contains expression (24) If you take some time to be tourist, which, according to SBrE grammar rules, should contain the indefinite article before the noun tourist, and thus, to be a tourist. The use of articles is one of the most challenging aspects of English grammar and certainly causes frequent departures from the standard in the new varieties of English, as was already indicated above.

The most conspicuous non-standard feature of the texts, however, lies not so much in their grammar at the level of structures, but punctuation. In three sentences the comma is missing before the word especially, which results in the ambiguity of the sentence, as it is unclear which element of the sentence the adverb refers to. It may be seen in text I, e.g., (25) I know I am going to miss the Head Office especially our editor, (26) It was not easy (...) to write all those stories especially end of the month (...), (27) write stories especially, I always relied on XY who was always on hand to drive me around to $X$ for community stories especially shack fires that frequently occurred in informal settlements (the comma missing in the relative clause after who is also to be noticed). Lack of comma may likewise be spotted in (28) I came across people with different personas some of them aggressive. Text II also contains two departures from the standard as concerns the use of punctuation, though of a slightly different calibre. While the lack of comma before where in the conditional clause (29) If your family or friends came to visit your city where would you go? is noticeable and causing a certain hesitation before the right meaning is arrived at, the insertion of the 
comma in sentence (30) Windhoek is full of statues and places, which have seen their fare share of existing evokes a greater degree of ambiguity by means of the use of a non-defining rather than defining relative clause, which implies that all the statues and places in Windhoek are considerably or equally old. It may thus be concluded that while the knowledge of vocabulary and grammar of the two writers points to their high fluency in English, some more subtle modifications of the standard use of the language stemming especially from the use of punctuation and articles can be detected even among educated Namibians.

Additionally, a number of features more typical of American English may also be noticed in the two texts, which is visible particularly in the context of the British model that Namibian English follows - not knowing the personal story of the authors we may assume the Americanisms may have reached here via the modern media. American structures may be noticed in phrases like (31) meet with these people, (32) It is a challenge for me to go work in a new environment (text I), while in text II the spelling of the verb (33) Marveling at the hawkers points to the American model too (it shows the author's inconsistency though, when we compare it to the form travelling a few lines above). Finally, a marked feature of the text is also the use of some informal items like journo (three times) and intro in text I, which may have also been copied from American English. Thus, in summary it has to be said that the columns, semi-formal in character, do manifest some departures from SBrE in different aspects, pointing to their more mesolectal nature, though they are by no means as striking as those which will be seen in the unedited texts found in the classified pages of the newspaper to be analysed below.

\section{Personal advertisements from classified pages}

These texts represent a fairly informal level of language use in the sense that they show how individuals write when they are not strictly monitored in terms of any official norms to observe. Yet the advertisements do need to be understandable to others and the fact that they are to be circulated in public does impose certain limitations on the freedom of expression in terms of grammar and spelling. However, as will be seen, these norms do appear to be flouted quite significantly when we scan the collected material in terms of British English norms, thereby reflecting the use of a written basilectal variant of English of members of lower social strata. These users of English, presumably of African background, are most certainly bi- or even multilingual, as beside the knowledge of English they also know at least their local tongue, which are many in Namibia (cf. Part 1), and, due to their social circumstances, which can be deduced from the content of the adverts, not very affluent or highly educated, unlike the authors of the previously analyzed texts.

The below analysis is based on 50 personal advertisements found in New Era of 6 September, 2013. They are all short, of average length of 20 words, e.g. (34) Iam looking for a job as a driver. I have driver lices (sic) code B and GP. Iam 21 years age. Although they are printed as a part of the newspaper, what can be deduced from the instruction given by the publisher is that they have been sent to the newspaper via text messages - and certain spelling modifications which some of the senders 
have used appear to reflect the new conventions of the electronic medium. In view of the fact, however, that the advertisements contain other types of departures from the SBrE conventions of spelling and grammar, it is not sure that the use of certain stylistic simplifications and spelling alternations was intended by the users or whether the posts show lack of acquaintance with the standard, which accidentally happened to overlap with the Computer Mediated Communication code. Some, however, are clearly such cases, e.g. (35) Plz call me on ..., (36) I hv grd 12, (37) $i$ have grd $12 \mathrm{nd}$ completed a certificate..., or else the use of am instead of $I \mathrm{am}$ as a marker of informality (though, admittedly, not necessarily expected in such a formal to semi-formal milieu).

What appears to be a visible modification in the texts in terms of grammar is, similarly as in the press releases, a non-standard use of articles when compared to British English. Altogether 8 items were recorded here, viz. (38) looking for job anywhere, (39) I am student, (40) Im 21 year's old lady, (41) I am looking for person to share a house. Although frequently omitted in CMC, the indefinite article absence in such cases as above cannot be treated as a simplification, for $a$ does appear in other advertisements or parts of the same advertisements, at times also misused, viz. (42) I am a boy 21 year looking for job anywhere, (43) I am 31 year old lady, (44) I am looking for person to share a house, (45) at affordable price, (46) looking for Sunday job, (47) notice of lost landed title. It may thus be concluded that the understanding and the standard use of articles, especially the indefinite one, has not been fully internalized by many of Namibian users of English of the lower social standing, thereby setting the right context for the development of some localized norms.

Another very noticeable problem that the authors of the texts seem to have in this particular communicative context is their age specification. Not many of them manage to use the whole phrase in agreement with the norm, viz. (48) I am a guy 26 years old. Others either omit the word old, e.g., (49) Am 26 years looking for a job, (50) I am boy 21 year, or the word years, e.g. (51) Iam 21 age. As can also be seen, the use of the plural form of years, wherever suitable, poses a problem, which is manifested by either the singular form where the plural is expected, or the other way round, or else an incorrect use of an apostrophe, e.g. (51) I am boy 21 year, (52) Im 21 year's old lady, (53) I am 31 years old lady. This basic piece of personal information, but at the same time a challenging nominal adjunct in terms of its use, appears to be a difficult one for non-native speakers of English in Namibia too, which the data collected here corroborate.

The remaining examples of grammatical departures from the standard are rather of a more ephemeral character, certainly also due to the limited number of the analyzed samples. The list shows, however, where Namibian speakers may potentially have a different understanding of grammar or gradually develop some localized norms:

- The use of prepositions in prepositional verbs, e.g. (54) I am currently looking a cross transfer from (...) to... (cf. looking for) and prepositional phrases, e.g. (55) a company which is need a driver (cf. in need of), (56) masters plumbing and renovations (cf. masters of), (57) in accordance the Tsumeb Town Planning System 
(cf. in accordance with). An alternative choice of prepositions can also be found in e.g. (58) on the $1^{\text {st }}$ week of October (cf. in the $1^{\text {st }}$ week).

- A non-standard use of progressive forms where the simple aspect is expected, viz. (59) am having code C1 driving licence (cf. I have) or (60) I am having a grade 12 and a diploma in hospitality (cf. I have). Such examples indicate lack of understanding of the standard distinction between the two aspects and a possible influence from American English, where the use of progressive forms is on the increase.

- Copy pronouns - only one example of such a use has been recorded, viz. (61) Roswita 26 and Clementine 33 we are looking 4 domestic work in... (cf. Roswita 26 and Clementine 33 are looking). However, as analyses dealing with features of $\mathrm{New}$ Englishes demonstrate (cf. Mesthrie 2000; Mesthrie, Bhatt 2008; Jenkins 2009, 2014), the use of copy pronouns, otherwise also called topicalization, appears to be one of the most typical features of post-colonial English, disregarding the actual area of use.

- The remaining examples contain instances of differently formulated phrases which may have stemmed from the sender's being in a hurry or lack of space, as a result of which irregularities can occasionally be caused by omission of too many elements, especially verbs and subjects, e.g. (62) I hv grd 12, certificate in adminsutration and computer literate. Also some other incongruities resulting from certain elements missing can be noted, viz. (63) am redy 2 start any day as possible even am in Otjiwarongo.

- Miscellaneous - (64) intends applying to the Municipal council (a non-standard verb form), (65) I am a gal, looking for Sunday job, ether is it laundry or just cleaning its ok, in which a non-standard subject-verb inversion appears, besides the lack of an apostrophe in the contracted form it's, 1 pant - 2 pants - an alternative analysis of pluralia tantum pants into a mass noun, which in this interpretation has a singular form.

The final part of the discussion of the analyzed texts concerns the problem of spelling. Besides the possible influence coming from the exposure to and use of electronic media mentioned above, quite numerous instances of erroneous spelling can certainly be found that rather unquestionably indicate the sender's lack of acquaintance with the standard form, at times even leading to ambiguities which can be solved only with the help of the context, as e.g. weaves which, correct as it looks, appears to be 'waves', as it can be deduced from the following sentence (66) weaves, cuts, highlights, braids, menicure and pedicure barbers (the misspelt menicure also needs to be noted). Other examples include ether (cf. either) as in (67) ether is it laundry or just cleaning, were we send faulty equipment (cf. where), (68) driver lices (cf. licence), (69) a young ledy (cf. lady), (70) am redy (cf. ready), (71) am argently loking 4 work (cf. urgently looking), (72) wensdy (cf. Wednesday), (73) electrick fence (cf. electric), (74) jur safety (cf. your). Many of the above examples appear to indicate indirectly that the incorrectly spelled forms follow the pronunciation of words, and that the pronunciation itself is not exactly identical to that of the Standard British English, e.g. ledy, redy, argently, which point to the simplification of diphthongs or the $r$-less pronunciation. 
The use of the word gal rather than girl is presumably also an outcome of the $r$-less pronunciation, though of course the word does exist in informal BrE.

Altogether, the above analysis has demonstrated that about a half of the nonstandard uses of grammar recorded in the collected material were to be found in the last subcategory of examples, i.e. the samples of basilectal use of English in Namibia. The number of the features which the authors of the advertisements used differently than in SBrE is not very extensive, yet meaningful. The limitations on other possible departures from the standard must have resulted from the character of the genre (for instance, an overall lack of references to the past in job advertisements and their restricted length) as well as the written medium utilized by the authors. The list of categories discussed above, does, however, corroborate the more general use of certain types of grammatical modifications found across post-colonial Englishes, which were briefly enumerated in part 1 of the paper, including the more specific reference to Steigertahl's (2015) examples found in Namibian English too. And thus the feature which appears to be most sensitive to alterations in New Englishes are articles, both the definite and the indefinite one, which, similarly as in the aforementioned sources, showed tendencies to either be omitted or used differently than in the standard. A very visible category of non-standard uses were also prepositional phrases, and thus an extension of phrasal verbs typically listed in literature as a feature of post-colonial Englishes, here manifested mainly by omissions of the prepositions which would otherwise be found in relevant forms of SBrE. A feature that specifically corroborates Steigertahl's observations is that of the overuse of the progressive forms in the contexts and phrases which otherwise would require simple verb forms. Otherwise worth mentioning are also the instances of copy pronouns as well as omissions of the subjects in the sentence, which have also been mentioned by other sources, though here they were represented only by one example each. Overall, the salience of the features listed above leads to an assumption that these are the features of grammar that may form the foundation of a new variety of Namibian English in the future when it reaches the Endonormative Stabilization and finally the Differentation phase (cf. Schneider 2007; Buschfeld 2014).

\section{Concluding remarks}

The overview contained in Part 1 of the paper outlined the linguistic situation in Namibia in some detail, focusing in particular on the use of English. The analysis of the written texts in Part 2, both of the official and personal character (especially billboards and newspaper releases), pointed to prestige planning with regard to the use of English assumed by the state in its attempting to disseminate positive feelings about the country, together with the use of English to carry the message. This can be interpreted as an encouragement for people to identify with the language that is native to only a small fraction of Namibian society (under $1 \%$ ).

The main objective of the paper was to focus on different manifestations of written English and investigate them in terms of their adhering to the norms of British 
English with respect to the social context of their use. Notably the comparison of the form of English used by journalists in newspaper texts and governmental billboards on the one hand and newspaper columns, and especially personal advertisements in newspapers on the other showed a clear diversity with regard to the level of the command of English between the analyzed groups of users, indicating visible departures from the norm in the language of the lower strata of the society. At the same time it demonstrated the existence of a visible social stratification as regards the use of English that hints at the existence of the acrolectal, mesolectal, and basilectal varieties of English in Namibia. The text analysis resulted in the identification of numerous departures from the Standard British English rules of spelling and grammar, notably concerning the knowledge of articles, use of prepositions and certain phrases, e.g. giving age. The spelling of words was also marked by frequent modifications, at times triggered by the CMC medium, but mostly stemming from the imperfect knowledge of the standard. In sum, it may be concluded that even though the variety of English used in Namibia does not have the typical colonial foundations, it still appears to share features with other new varieties of English commonly found in the Outer Circle, which, in turn, may lead to a formation of a separate standard in the future.

\section{References}

Buschfeld S. 2014. English in Cyprus and Namibia. A critical approach to taxonomies and models of World Englishes and Second Language Acquisition research. - Buschfeld S., Hoffmann T., Huber M., Kautzsch A. (eds.). The evolution of Englishes. The Dynamic Model and beyond. Amsterdam, Philadelphia: 181-202.

Collins dictionary. [available at: www.collinsdictionary.com/dictionary/english/distributor].

Deumert A. 2009. Language planning and policy. - Mesthrie R., Swann J., Deumert A., Leap W.L. (eds.). Introducing sociolinguistics. [2 ${ }^{\text {nd }}$ edition]. Edinburgh: 371-406.

Jenkins J. 2009. World Englishes. A resource book for students. [2 ${ }^{\text {nd }}$ edition]. London, New York. Jenkins J. 2014. Global Englishes. A resource book for students. [3 ${ }^{\text {rd }}$ edition]. London, New York. Kirkpatrick A. 2007. World Englishes: Implications for international communication and English language teaching. Cambridge.

Mesthrie R. 2009 Language contact 2: Pidgins, creoles and 'New Englishes'. - Mesthrie R., Swann J., Deumert A., Leap W.L. (eds.). Introducing sociolinguistics. [2 ${ }^{\text {nd }}$ edition]. Edinburgh: 271-308.

Mesthrie R., Bhatt R. 2008. World Englishes. The study of new linguistic varieties. Cambridge. Platt J.T. 1975. The Singapore English speech continuum and its basilect "Singlish" as a "creoloid”. - Anthropological Linguistics 17: 363-374.

Schneider E. 2007. Postcolonial English: Varieties around the world. Cambridge.

Steigertahl H. 2015. Presentation: English in Namibia - A new variety? An empirical study of language use and variety status in four Namibian communities. [available at: www. academia.edu/12861565/Presentation_English_in_Namibia_A_New_Variety].

Stell G. 2009. Is there a Namibian Afrikaans? Recent trends in grammatical variation in Afrikaans varieties within and across Namibia’s borders. - Stellenbosch Papers in Linguistics PLUS 39: 85-105. 
Stell G. 2014. Uses and functions of English in Namibia's multiethnic settings. - Journal of World Englishes 33.2: 223-241.

The free dictionary. [available at: www.thefreedictionary.com/shebeen]. Wiktionary. [available at: en.wiktionary.org/wiki/distributer].

Yano Y. 2001. World Englishes in 2000 and beyond. - World Englishes 20.2: 119-132. 